\title{
TECNOLOGIAS DA INFORMAÇÃO E COMUNICAÇÃO E AS METODOLOGIAS ATIVAS: ELEMENTOS PARA O TRABALHO DOCENTE NO ENSINO SUPERIOR
}

\author{
INFORMATION AND COMMUNICATION TECHNOLOGIES AND ACTIVE \\ METHODOLOGIES: ELEMENTS FOR TEACHING WORK IN HIGHER \\ EDUCATION
}

DOI: http://dx.doi.org/10.23926/RPD.2526-2149.2018.v3.n2.p798-812.id281

\section{Priscila Miranda de Carvalho Coletto Mestranda em \\ Medotodologias para o \\ Ensino de Linguagens e suas \\ Tecnologias (UNOPAR). \\ Coordenadora e Docente do \\ Curso Superior de \\ Enfermagem da Faculdade \\ Anhanguera de Valparaíso. \\ priscilacoletto@gmail.com}

\section{Okçana Battini}

Doutorado em Educação

(UFPR).

Professora Titular

(UNOPAR).

okcana@unopar.br

\section{Edenar Monteiro \\ Doutora em Educação \\ (UFMT).}

Professora da Universidade de Cuiabá (UNIC).

edenar.monteiro@kroton.co $\underline{\text { m.br }}$
Resumo: A utilização da Tecnologias Digitais de Informação e Comunicação (TDICs) e das metodologias ativas no espaço universitário apontam para uma nova forma de estabelecer o trabalho e papel dos professores e alunos no processo de ensino aprendizagem. Nesse sentido, esse artigo traz os resultados de uma pesquisa que teve como objetivo compreender a percepção dos docentes do curso de Enfermagem sobre a utilização das TDICs como elementos mediadores da aprendizagem. Trata-se de uma pesquisa de caráter qualitativo realizada por meio estudo de caso com 6 professores do curso de Enfermagem de uma universidade privada do estado de Goiás. A incorporação das ferramentas tecnológica tende a uma prática pedagógica mais enriquecedora, potencializando a interação e integração bem como a capacidade de compreensão dos conhecimentos, por parte de professores e alunos. Na área de Enfermagem, grandes esforços têm sido realizados com a finalidade de extrair maiores benefícios da utilização das TDICs para obter e/ou garantir um grau maior de qualidade no Ensino. Diante disso permitiu apontar que o ensino de enfermagem mediado pelo uso das TDICs configura-se um desafio exigindo dos alunos, docentes e instituições de ensino superior mudanças na postura frente ao processo educacional.

Palavras-chave: Tecnologias Digitais de Informação e Comunicação. Ensino de Enfermagem. Trabalho Docente. Formação de Professores.

\begin{abstract}
The use of Digital Information and Communication Technologies TDICs and the active methodologies in the university space point to a new way of establishing the work and role of teachers and students in the process of teaching learning. In this sense, this research aimed to understand the perception of teachers of the Nursing course on the use of TDICs as mediators of learning. It is a qualitative research carried out through a bibliographical survey and case study with 6 teachers of the Nursing course of a Private University of the State of Goiás. The incorporation of technological tools tends to a more enriching pedagogical practice, interaction and integration as well as the ability to understand the knowledge, by teachers and students. In the Nursing area, great efforts have been made to extract greater benefits from the use of the TDICs to obtain and / or guarantee a higher degree of quality in the Teaching. Given this, it was possible to point out that nursing education mediated by the use of TDICs is a challenge requiring students, teachers and institutions of higher education changes in the posture in front of the educational process.
\end{abstract}

Keywords: Digital Information and Communication Technologies. Nursing education. Teaching Work. Teacher training. 


\section{INTRODUÇÃO}

O desenvolvimento das tecnologias de informação e comunicação (TDICs) tem modificado a sociedade em quase todas as áreas do conhecimento. O campo educacional não é uma exceção, pois trata-se de uma área onde os sujeitos passam parte da sua vida, desde a educação básica ao ensino superior sendo que a utilização das TDICs tem potencializado os processos de ensino aprendizagem. Importante salientar que os jovens estão cada vez mais conectados a essas tecnologias, estabelecendo novas e diferentes relações com o conhecimento. Nesse sentido, torna-se necessário, por parte das escolas e Universidades, a utilização de novas abordagens e métodos de ensino para que consigam manter a atenção e a motivação desses alunos.

Um elemento importante nesse contexto é a chamada educação blended ou ensino híbrido, que é a mescla de atividades presenciais e online, realizadas por metodologias que levem novos desafios para os atores do processo de ensino aprendizagem: professores e alunos. Essa educação sustenta-se na estimulação dos alunos por parte dos professores, por meio da utilização das metodologias ativas e as TDICs em todo o processo educativo, sendo que o trabalho pode ser realizado de forma individual ou em grupo. Esses elementos estão presentes cada vez mais no espaço universitário.

Sendo as TDICs, o ensino hibrido e as metodologias ativas ferramentas importantes para o desempenho do trabalho educativo do professor do Ensino Superior, esse estudo traz a seguinte indagação: Como os docentes do curso de enfermagem estão utilizando as TDICs em suas práticas pedagógicas? Diante deste contexto, o artigo tem como objetivo fazer uma análise a respeito da percepção e utilização das TDICs pelos docentes do curso de enfermagem como instrumentos mediadores da aprendizagem no ensino superior. Para isso, torna-se importante compreender como a questão do ensino híbrido aponta para a necessidade do professor do ensino superior, repensara sua metodologia de trabalho.

\section{REFERENCIAL TEÓRICO}

Estudos evidenciam que o processo educativo quando mediado pelas diversas tecnologias educacionais permitem a combinação de várias mídias o que possibilita a otimização do tempo de estudo, despertando nos alunos a autonomia diante de sua aprendizagem, auxiliando-os na resolução de problemas e enriquecendo os debates sobre os temas em discussão (VALATIS et al., 2005). 
Muitos são os recursos tecnológicos disponíveis para utilização em sala de aula. Há softwares multiuso, Ambientes Virtuais de Aprendizagem (AVA), ferramentas colaborativas, vídeos, smarthphones, celulares, tabletes, notebooks, aplicativos em que professores e alunos podem se conectar, comunicar e trocar ideias independente de distância. Nesse processo é essencial que o professor tenha o seu planejamento pedagógico (plano de aula, conteúdo, avaliação, didática) atrelado às TDICs, visto que essa articulação possibilita ao aluno maior autonomia sobre a decisão de acessar ou não o material, conforme o seu interesse e a sua disponibilidade. Considerando os benefícios do emprego desses recursos no ensino e aprendizagem, os docentes devem estar atentos às vantagens que as TDICs oferecem para seu trabalho, como por exemplo a fácil e rápida visualização pelos alunos dos conteúdos propostos pelo professor levando-os a pensar e relembrar os conteúdos estudados, sendo de fácil utilização e despertando o interesse do aluno na resolução dos problemas propostos, desburocratizando o processo formativo e auxiliando o aluno na tomada de decisões (TAVARES; COSTA;OLIVEIJO, 2018).

Para Bacich e Moran (2018) duas categorias são bem significativas para pensar essa nova abordagem: as metodologias ativas e o ensino híbrido. As metodologias ativas mobilizam os atores envolvidos no ato de ensino aprendizagem (professor e aluno). O professor não mais "ensina" o aluno, ele passa a ser um mediador, um orientador que oferece ferramentas para que o aluno construa seu conhecimento e todo o processo de ensino se baseia em descobertas, questionamentos, pesquisas. $\mathrm{O}$ aluno é colocado no centro desse procedimento, procurando despertar a reflexão, a participação, o envolvimento direto com a aprendizagem. Já o ensino híbrido, sustenta-se pela modelagem entre o ensino presencial e o virtual, ou seja, partes do processo de ensino aprendizagem se efetivam na sala de aula tradicional e parte pode ser realizado em vários lugar, mediados pelas tecnologias da informação e comunicação, como computadores, tablets, smartphones, etc.

Um exemplo da utilização desse processo é o KLS 2.0 (Kroton Learning System versão 2.0). Segundo Carvalho (2018) o grupo Kroton ${ }^{1}$, adotou a partir de 2014 o KLS 2.0 que é o modelo pedagógico utilizado pelas Universidades do grupo, que mescla a utilização do ensino híbrido com as metodologias ativas, tendo a intenção de melhorar e maximizar o processo de aprendizagem. Carvalho (2018) aponta que o KLS 2.0 é sustentado por um currículo baseado

\footnotetext{
${ }^{1}$ Todas as autoras desse trabalho são professoras das Universidades que fazem parte do grupo Kroton Educacional e utilizam em sua prática pedagógica o KLS 2.0.
} 
por competências, tendo a sala de aula invertida e a aprendizagem baseada em problemas como direcionadores da prática pedagógica.

Importante salientar que o ensino híbrido é um desafio, visto que não se trata de usar a tecnologia como pretexto, é necessário ter uma finalidade, ou seja, o processo educativo. Nesse sentido, Moran et al. (2000, p. 144), fazem um alerta:

[...] a tecnologia possui um valor relativo: ela somente terá importância se for adequada para facilitar o alcance dos objetivos e se for eficiente para tanto. As técnicas não se justificarão por si mesmas, mas pelos objetivos que se pretende que elas alcancem que, no caso, serão de aprendizagem

Assim, para a realização da ação docente, o professor precisa ter claro quais objetivos pedagógicos que atingir, pois as TDICs são ferramentas que passam a ser inseridas no processo de ensino, sendo essencial que o professor utilize como fonte potencializadora da aprendizagem e não um suporte para realizar metodologias tradicionais de ensino, com outra roupagem.

As tecnologias digitais exigem do professor a postura de facilitador do processo ensinoaprendizagem, - tornando-se dinâmico, mediador, articulador, crítico e criativo, provocando uma prática pedagógica que instiga o posicionamento, a autonomia, a tomada de decisão e a construção do conhecimento (BENHENS, 1999, p. 91). Segundo Lévy (2008, p. 163),

Não se trata de usar as tecnologias a qualquer custo, mas sim de acompanhar consciente e deliberadamente uma mudança de civilização que questiona profundamente as formas institucionais, as mentalidades e a cultura dos sistemas educacionais tradicionais e, sobretudo os papéis de professor e de aluno

Conforme Moran et al. (2000), não há um modo específico de como utilizar as tecnologias digitais. Cada professor deve procurar a forma que mais lhe ajude na maneira de trabalhar com os alunos, que mais lhe facilite a comunicação e que dê melhores resultados para o aprendizado. Contudo ensinar com as novas tecnologias só trará benefícios se estivermos dispostos a enfrentar os novos paradigmas convencionais do ensino em que professor deixará de ser o transmissor de conhecimentos e será o mediador, motivador, orientador.

Segundo Coscarelli (2007, p.91 apud Reis, Nantes e Maciel, 2018, p.251), “a tecnologia não pode estar dissociada da educação: ela é parte integrante do processo educativo e não deve ser tratada isoladamente". As autoras apontam que existe uma diversidade de ferramentas tecnológicas e que novos paradigmas passam a fazer parte da educação. Segundo as autoras:

[...] para a realização de uma boa atividade pedagógica mediadas pelas tecnologias da informação e comunicação, é necessário um “projeto de educação tecnológica” com respaldo teórico. No entanto, quando se trata de literaturas que embasam a educação tecnológica, observa - se a necessidade de uma maior intersecção entre a teoria e a prática do professor. (REIS, NANTES e MACIEL, 2018, p. 252) 
Nesse sentido, uma questão importante no que tange as TDCIs não é somente a utilização da mesma no espaço escolar. Importante também é a necessidade de avaliar o impacto delas nas atividades de ensino e aprendizagem. Nesse contexto, é necessário entender a questão do letramento digital, como sendo um elo para a articulação entre a tecnologia e o trabalho/formação docente. Segundo Reis, Nantes e Maciel (2018) a concepção de alfabetização e de letramento alcança novas abordagens para a compreensão da utilização dessas novas formas de linguagens, no caso, a linguagem digital. As autoras indicam os estudos de Kleiman (1995), Rojo (2012; 2009), Soares (2009), Coscarelli (2007) que apontam alternativas para a melhoria do ensino de linguagem e suas tecnologias.

Para Reis, Nantes e Maciel (2018, p.250) existe uma hipótese de que os professores podem não estar preparados para a inserção das tecnologias no contexto escolar.


diferentes formas de linguagem e de textos que circulam em nosso cotidiano. Um caminho possível é investir na formação continuada dos docentes, para que eles possam se apropriar, paulatinamente, da tecnologia como ferramenta para o ensino.

A aprendizagem mediada pelas TDCIs só fará sentido e será eficaz se os atores do processo (professor e aluno) atribuírem significados às informações recebidas. "Se, por um lado, diariamente, recebemos uma gama enorme de informações, por outro, saber filtrar essas informações e descartar aquelas que não vão agregar nenhum conhecimento faz parte do letramento digital." (REIS, NANTES e MACIEL, 2018, p. 251)

Diante disso, segundo Reis, Nantes e Maciel, (2018, p.255) formar professores para o letramento digital não é pensar na técnica, mas sim, em desenvolver competências e habilidades específicas, que devem ser (re)elaboradas, (re)adaptadas, conforme a demanda vivenciada pelo professor, pois a tecnologia está, cada vez mais, estreitamente vinculada a todo e qualquer processo de trabalho.

Neste sentido a tendência pedagógica atual, exige o letramento digital, via conhecimentos teórico, pedagógico, didático, bem como a formação continuada como condições indispensáveis para o trabalho docente. A educação atual se encontra diante de um grande desafio: constituir um espaço de mediação entre o aluno e o mundo tecnológico. Para isso, faz-se necessário que o professor domine as novas tecnologias, que tenha uma nova qualificação e que atenda às expectativas requeridas por este novo paradigma. Daí a importância de que se reveste a preparação de profissionais no domínio dessas tecnologias, para que se tornem capazes de pensar e de participar ativamente desse processo de mudança. 
Tendo esse contexto como pano de fundo percebemos uma grande contradição no que tange a prática docente. A utilização das metodologias ativas como ferramentas de auxílio da pratica docente, na maioria das vezes, é resultado de mudança de postura teórico prática do professor. Porém ainda existe um gama de profissionais que reproduzem a forma como foram ensinados nas escolas e nos cursos de graduação. Isso não significa que eles não conhecem a importância dos princípios educativos, mas encontram, em seu cotidiano, dificuldade de colocalos em prática.

Essa questão pode ser articulada com o processo de trabalho e formação dos professores. Schön (1995) aponta a necessidade de uma "reflexão sobre a prática", sendo que nesse processo o professor percebe suas fragilidades, reconhece as problemáticas e propõe soluções. No entanto, para chegar até essas soluções a prática deve ser revista e reconstruída constantemente, com o auxílio coletivo dos sujeitos envolvidos no ato pedagógico. Corroborando com essa leitura é necessário que os professores tenham claro quais saberes serão mobilizados para essa transformação, que acontecerá mediante a articulação entre os saberes acadêmicos, saberes especializados e saberes oriundos da experiência - para alcançar êxito (Perrenoud, 2002, p. 11). Portanto, é imprescindível que novas metodologias sejam difundidas entre os professores, para que as práticas escolares possam ser reformuladas. É importante, não somente informá-los sobre como utilizar as novas metodologias, mas também afirmar que elas precisam ser vivenciadas para que o discurso e prática sejam articulados.

\subsection{A IMPORTÂNCIA DAS TDICS NO ENSINO DE ENFERMAGEM}

A formação contemporânea do aluno de Enfermagem exige articulação entre teoria e prática, diversificação dos cenários de aprendizagem, metodologias ativas, flexibilidade curricular, a interdisciplinaridade, atividades complementares, a avaliação da aprendizagem, assim como do processo de acompanhamento, sempre tendo como foco o aluno que é o sujeito desse processo de formação.

As Diretrizes Curriculares Nacionais do Curso de Graduação em Enfermagem (BRASIL, 2001) apontam nos Art.4 - inciso III “[...] a comunicação envolve comunicação verbal, não-verbal e habilidades de escrita e leitura; o domínio de, pelo menos, uma língua estrangeira e de tecnologias de comunicação e informação" e no Art.5 inciso XV "usar adequadamente novas tecnologias, tanto de informação e comunicação, quanto de ponta para o cuidar de enfermagem" 
$\mathrm{Na}$ área de Enfermagem, grandes esforços têm sido realizados com a finalidade de extrair maiores benefícios da utilização da TDCIs para obter um grau maior de qualidade no Ensino. O uso dessas tecnologias contempla a existência de um objeto de trabalho dinâmico, em contínuo movimento, não mais estático ou passivo (LOPES; SILVA; ARAÚJO, 2006).

As tecnologias digitais representam importantes ferramentas para o ensino de enfermagem e vêm transformando a maneira de ensinar e aprender, permitindo versatilidade, interatividade e flexibilidade de tempo e de espaço (TAVARES; COSTA; OLIVEIJO, 2018).

Segundo Scheffer, Rubim e Eva (2010, p. 74) as TIDICs potencializam uma prática curiosa e desafiadora para os alunos de Enfermagem, o que impacta diretamente na construção de sua autonomia enquanto aluno e futuro enfermeiro. "No caso específico do ensino de Enfermagem, o oferecimento de momentos em que o aluno precisa decidir e exercer sua autonomia pode rever situações nas quais ele apenas memoriza o conteúdo sem conseguir realmente conhecer ou aprender sobre o objeto estudado"

Tavares, Costa e Oliveijo (2018) apontam que as melhores práticas de ensino aprendizagem na Enfermagem articulam metodologia pedagógica problematizadora e recursos educacionais digitais, que permitem ao aluno o desenvolvimento da capacidade analítica e crítica na resolução de um problema.

Os recursos educacionais na forma digital como ambientes virtuais de aprendizagem, hipertexto, jogo educativo, os softwares, aliadas a aulas práticas, tanto em laboratórios quanto em simulações possibilita minimizar erros, pois os alunos irão progressivamente adquirindo habilidades possibilitando um processo de ensino-aprendizagem que garante o alcance de melhores resultados no ensino (TANAKA et al., 2010).

Baseado nessa questão, Scheffer, Rubim e Eva (2010) apontam que os docentes da área de saúde precisam realizar uma prática mediadora em sala de aula, com a utilização das TDICs, seja em situações didáticas, seja em sua vida pessoal, assim como também deve possuir uma contínua reflexão sobre as consequências sociais e éticas de suas escolhas tecnológicas.

Scheffer, Rubim e Eva (2010) levantam uma questão importante: a necessidade de maiores investimentos nesta área (ensino de enfermagem mediados pelas TDICs) visto que é uma área que não pode ficar à margem do atual processo de desenvolvimento tecnológica. Assim, não é delegado somente ao docente de enfermagem a utilização das TDICs em seu cotidiano na Universidade, mas também as Instituições de Ensino Superior, que devem estimular a participação coletiva de todos os atores envolvidos no processo de ensino aprendizagem. 


\section{Metodologia}

A pesquisa sustentou-se pela abordagem qualitativa, tendo o estudo de caso como procedimento metodológico de condução do trabalho investigativo. A escolha desses procedimentos de pesquisa adapta-se bem aos objetivos traçados nesse estudo, pois possibilita o entendimento do fenômeno em sua totalidade, no âmbito de nosso espaço de pesquisa. Trabalhamos com essa perspectiva visto nossos objetivos não estarem relacionado com a linearidade de dados e teorias e, tampouco, com o número de pessoas que vão prestar informação, mas com os significados que esses sujeitos irão verbalizar em função do que estamos buscando na pesquisa (MARTINELLI, 1999).

A pesquisa foi realizada em uma instituição de ensino superior privada, no interior do Estado de Goiás e se deu em 3 etapas: exibição de vídeo, coleta de dados e consolidação, análise e socialização dos dados. A amostra foi constituída por um total de 6 docentes do curso de Enfermagem, que trabalharam, durante o $1^{\circ}$ semestre do ano de 2018 , com um novo modelo avaliativo chamado de avaliação continuada por pontos, realizada via TDICs. Esse modelo de avaliação é um dos diversos modelos utilizados pela instituição. O aluno é avaliado por meio de 5 atividades, sendo que duas são elaboradas e aplicadas pelo professor em sala de aula e as demais são realizadas pelo aluno no AVA com correção automática. Nosso objetivo era compreender a percepção que os docentes têm sobre a utilização das TDICs como instrumentos mediadores da aprendizagem no curso de Enfermagem.

\subsection{Etapas da Pesquisa}

Etapa 1: Exibição de vídeo com a temática "Convergência" (que pode ser encontrado no link: https://www.youtube.com/watch?v=rbXJMAFRM7I) que trata sobre a quarta revolução industrial para os professores. Klaus Schwab (2016, p.24) relata que essa revolução irá " desdobrar-se em mudanças econômicas, sociais e culturais de proporções tão fenomenais que chega a ser quase impossível prevê-las ". O vídeo exibido nesta etapa, é classificado na categorização de Bartolomé (1999), como vídeo impacto que são vídeos provocadores, que não se preocupam tanto em dar uma informação completa e são destinados à motivação inicial sobre um tema ou assunto.

Etapa 2: Coleta de dados: Posterior a exibição do vídeo, como instrumento de coleta de dados foi aplicado um questionário aberto via ferramenta Formulário do Google Drive. O questionário on-line é um instrumento que possibilita ao pesquisador: baixo custo, economia de tempo, facilidade quanto ao uso, ausências de restrições geográficas e espaciais. Na forma 
on-line por meio do Google Docs, o questionário foi enviado aos 6 professores sendo que somente 5 responderam.

Etapa 3: Consolidação e socialização dos dados: Para a consolidação e interpretação dos dados, utilizou-se o método de análise de conteúdo segundo Bardin (2004). Os dados foram coletados seguindo procedimentos éticos como a explicação dos objetivos da pesquisa.

\section{Resultados}

Os docentes foram classificados por Docente de Enfermagem e número (ex. DE1). Importante salientar o tempo de serviço na docência dos professores: 3 professores estão na docência há menos de 1 ano e 2 professores há mais de 3 anos. Foi questionado se os professores realizam o uso das TDICs em suas práticas pedagógicas e como se deu a experiência. Todos os docentes relataram que já fazem uso de tecnologias digitais em sala de aula e nos ambientes Virtuais de Aprendizagem:

\footnotetext{
"Eu utilizo práticas digitais durante a aula, [...] os alunos ficam mais participativos com o uso de tecnologias" (DE1).

"Sim, na minha instituição de trabalho existe situações problemas [...] incluo a mesma situação em vídeos deixando o aluno cada vez mais preso ao assunto." (DE2).

"Sim. Contudo observo que o desenvolvimento tecnológico no Brasil é lento, mas de extrema necessidade é a sua utilização no processo educacional [...]" (DE3).

"Uso de animações ou vídeos [...]" (DE4).

"Uso vídeos e aplicativos de celular em salas de aula. Experiência bastante inclusiva." (DE5).
}

Verificamos que todos os professores utilizam as TDICs no seu trabalho com os alunos, inclusive elencando que os mesmos ficam mais "participativos" e "presos ao assunto" do que em uma aula sem a utilização dos recursos, indicando que os alunos se sentem mais "inclusos" no processo de aprendizagem. Nesse sentido, precisamos ter claro que o uso da tecnologia como recurso pedagógico deve ser uma escolha bem pensada por parte dos docentes no processo ensino-aprendizagem. Não se deve confundir tecnologia com a aquisição de equipamentos. Mandar que os alunos apertem uma tecla o computador para assistirem passivamente a algum vídeo sobre determinado assunto, não é a realização da mediação das TDICs no processo de aprendizagem. As TDICs por elas mesmos não passam de um meio, ou um artefato que armazena as informações e exige uma técnica de acesso.

Valente (1988) aponta que é essencial a compreensão de como se efetiva a articulação dos recursos tecnológicos a partir de uma vertente crítica do processo de ensino aprendizagem, para a superação das abordagens meramente instrucionistas. 
Diante disso é necessário por parte do professor a didática, quer dizer, como o professor utiliza as TDICs na transposição dos conteúdos, pois caso não tenha essa preocupação, as mesmas viram meio de transmissão do conhecimento de forma passiva e não possibilidade de construção autônoma do conhecimento por parte do aluno.

Um segundo questionamento busca compreender quais os pontos críticos, dificuldades ou desafios na inclusão de TDICs no cotidiano do seu trabalho.

“[...] dificuldade na adesão por parte de uma parcela dos alunos” (DE1).

“O maior desafio é estimular o aluno a utilizar as ferramentas presentes” (DE2).

"Muitos alunos querem a aula mais convencional [...] (DE3)".

Fazer com que eles entendam a importância da participação deles no processo de aprendizagem é um dos desafios da atualidade" (DE4).

“Alguns alunos não têm acesso a internet ou não sabem utilizar a tecnologia” (DE5).

A maioria identificou que há resistência e dificuldade por parte dos alunos. Pacheco (1997), reitera a necessidade da função suporte técnico/teórico no processo de aprendizagem, tendo em vista a habilidade tecnológica do docente para que o estudante possa utilizar as tecnologias aplicadas ao processo educativo de forma competente e segura. Essa questão também pode ser entendida pela cultura escolar dos alunos, visto que, na grande maioria dos casos, a educação básica é realizada de forma tradicional, sem a utilização de forma significativa, das TDICs, o que não gera nos mesmos a cultura digital.

Buckingham (2010) ilustra bem ao discutir algumas das especificidades da cultura digital. Ele alerta para o fato de que nem tudo que está veiculado no computador pode realmente ser chamado de digital. Por exemplo, um livro que foi transformado em arquivo PDF simplesmente é um livro digitalizado, não é digital. Não cabe mais ao sujeito ser apenas alfabetizado, agora ele precisa ser letrado, ou seja, não apenas conhecer os signos e símbolos de sua língua, mas saber interpretá-los, compreendê-los e usá-los na sua vida social, política e histórica.

Esses debates conduzem ao que as autoras (Reis, Nantes e Maciel, 2018) e Buckingham (2010, p. 339) apontam como letramento digital "O conjunto de competências necessárias para que o indivíduo entenda e use a informação de maneira crítica e estratégica, em formatos múltiplos, vinda de variadas fontes e apresentada por meio do computador-internet, sendo capaz de atingir seus objetivos".

Diante disso foi indagado se os docentes se consideram preparados para utilizar as TDICs em seu cotidiano de trabalho. Apenas a DE5 opinou não estar preparada. Os outros professores levantaram que: 
"Estou em desenvolvimento constante" (DE1).

“[...] sou mestre, mas em nenhum momento do processo formativo foram realizadas inserções nessa área.” (DE2).

"Preciso melhorar no aspecto da busca por recursos tecnológicos adequados para minha área[...]”. DE3

"Sim, porém a tecnologia é algo com mudanças constantes [...]." (DE4).

Scheffer, Rubim, Eva (2010) apontam em seu estudo que muitos docentes e alunos do curso de enfermagem apresentam-se ainda resistentes quanto ao emprego desses recursos, pois para poderem utilizá-los são necessários alguns conhecimentos básicos sobre informática, o que pode tornar-se um transtorno para os avessos à tecnologia computacional, sempre em constante transformação. No que se refere ao docente, Libâneo (2010, p. 14) alerta que o professor teme a tecnologia, que ela o substitua, pensando erroneamente. Contudo é fundamental ao professor alfabetizar-se no mundo das tecnologias para poder atender a nova geração de alunos que está recebendo.

No que se refere à necessidade de formação e capacitação para o exercício da docência, buscou-se entender quais estratégias a Universidade pode realizar para que o professore faça uso das novas tecnologias e ser mediador? Todos os entrevistados afirmaram que se faz necessário um treinamento contínuo, formação para uso de ferramentas:

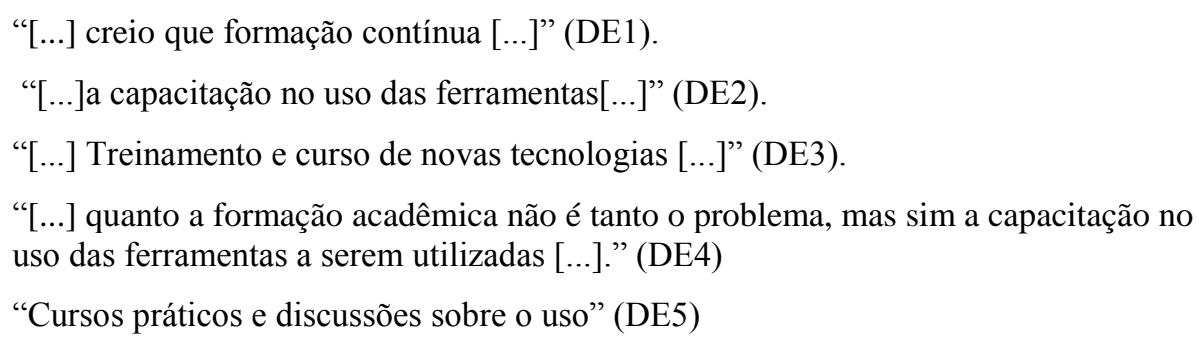

Frente às mudanças sociais desencadeadas pelas tecnologias digitais, novos desafios permeiam o ensino superior, assim faz-se necessário que as instituições de ensino proporcionem aos seus professores uma formação compatível com tais avanços. Em relação aos processos mediacionais, Moran et al (2000) entende que a ação e o comportamento do docente devem ser de facilitador, incentivador ou motivador da aprendizagem, tornando-o uma ponte entre o aprendiz e sua aprendizagem.

Por conta dessas mudanças, Nóvoa $(2009$, p.4) aponta que os "professores reaparecem, neste início do século XXI, como insubstituíveis não só na promoção da aprendizagem, mas [...] no desenvolvimento de métodos apropriados de utilização das novas tecnologias”.

França e Battini (2015) consideram que é necessário reformular os cursos de formação para o uso as TDICs. As autoras apontam que ainda existe uma tendência ao se pensar cursos 
de capacitação docente vinculados a uma instrução sobre o uso de máquinas, aplicativos... e não uma relação entre esses elementos e novas metodologias de ensino vinculados ao conteúdo. Segundo as autoras:

[...] os professores utilizam-se desses materiais (softwares) pois, como participaram de formações insuficientemente, reproduzem com os computadores os mesmos procedimentos que estavam utilizando anteriormente, assim as mudanças paradigmáticas são insignificantes e a utilização desses recursos tecnológicos é o menos adequado. (FRANÇA; BATTINI. 2015, p.10)

Kenski (2003, p. 77). também sustenta essa discussão, quando aponta que:

Instruí-los sobre o uso das máquinas - o conhecimento superficial do hardware e dos softwares industrializados disponíveis em cursos de curta duração, para o adestramento tecnológico, ou mesmo em séries de cursos para a aquisição da fluência digital. Consideram também que é suficiente o simples treinamento para a utilização dos principais programas: processadores de textos, programas básicos do Office e softwares educativos.

Por meio da análise dos dados infere-se que é necessário que a Instituição intervenha com estratégias, a partir da identificação dos problemas no contexto das tecnologias, que permitam a construção ativa do conhecimento por parte do professor e do aluno, concretizando a cultura digital dentro da Universidade. Assim, torna-se essencial por parte da Universidade e do professor articular o planejamento do modelo acadêmico, com os processos de ensino aprendizagem mediados pelas tecnologias. Importante também é que os professores tenham autonomia para escolher quais recursos são mais adequados para cada espaço e grupo de alunos. Para isso é essencial, além da consolidação da cultura digital a disseminação do letramento digital de todos os atores envolvidos no processo de ensino e aprendizagem, propondo não apenas uma utilização instrumental, mas a incorporação vivencial, investigativa e transformadora das tecnologias nos processos de ensinar e aprender.

\section{CONSIDERAÇÕES FinaIS}

A discussão sobre a inserção dos docentes da enfermagem no panorama do ensino utilizando tecnologias ainda é incipiente. É necessário que as instituições de ensino superior adotem políticas de investimento na capacitação tecnológica docente e discente, bem como na construção de competências, habilidades e conhecimento nas áreas de tecnologia da informação e de educação para que as mesmas sejam revertidas em novas estratégias de ensino.

Diante deste contexto, o processo de consolidação das TDICs no espaço Universitário exige que o professor e aluno saibam utilizar os meios tecnológicos voltados aos processos educativos não de forma instrucional, mas sim, potencializando o processo de construção do conhecimento. Não é um caminho fácil a utilização de novos recursos tecnológicos em um 
ambiente já estabelecido e com práticas bem definidas. Entendemos que os desafios são muitos, como a resistência que ainda se encontra entre os docentes e discentes. Acreditamos que existe a necessidade, de forma colaborativa dos atores do processo, docente e alunos, sustentados pela estrutura Universitária de formas consolidadas de capacitação para a consolidação da cultura e o letramento digital.

É preciso entender a importância da utilização e mediação das TDICs. Não existe um padrão de utilização das TDICs em sala de aula, o professor deve conseguir desenvolver habilidades que o permita ter o discernimento necessário em tratar a especificidade dos alunos juntamente com a complexidade e importância do conteúdo a ser ministrado e assim dimensionar como e quais as ferramentas tecnológicas serão utilizadas para aquela situação específica e assim conseguir promover formas que facilite ao aluno a devida apropriação dos conteúdos.

\section{REFERÊNCIAS}

BACICH, Lilian.; MORAN, José. Aprender e ensinar com foco na educação híbrida. In: Revista Pátio, n²5, p.45-47. São Paulo: ECA/USP, 2015. Disponível em: < http://www2.eca.usp.br/moran/wp-content/uploads/2015/07/hibrida.pdf $>$ Acesso em: 13 jun. 2018.

BACICH, Lilian.; MORAN, José. Metodologias Ativas para uma Educação Inovadora: Uma abordagem teórico-prática. Porto Alegre: Penso, 2018.

BARDIN, Laurence. Análise de conteúdo (3ª ed.). Lisboa, Portugal: Edições 70, 223p. 2004.

BARTOLOMÉ, Antonio.Ramón. Nuevas tecnologías em el aula. Barcelona: Grão, 1999

BEHRENS, Marilda Aparecida. O paradigma emergente e a prática pedagógica. Curitiba: Champagnat, 1999.

Brasil. RESOLUÇÃO CNE/CES N 3, DE 7 DE NOVEMBRO DE 2001. Institui Diretrizes Curriculares Nacionais do Curso de Graduação em Enfermagem. Disponível em: http://portal.mec.gov.br/cne/arquivos/pdf/CES03.pdf

BUCKINGHAM, David. Cultura digital, educação midiática e o lugar da escolarização. Educação e Realidade, Porto Alegre, v. 35, n. 3, p. 37-58, 2010. Disponível em: http://seer.ufrgs.br/educacaoerealidade/article/view/13077/10270 . Acesso em: 12 out. 2018.

CARVALHO, Adriano. Almeida de. KLS 2.0: uma ferramenta disruptiva de ensino. Dissertação de Mestrado em Ensino. Universidade de Cuiabá. 2018.

COSCARELLI, Carla. Viana; RIBEIRO, Ana Elisa (Orgs). Letramento digital: aspectos sociais e possibilidades pedagógicas. 2. ed. Belo Horizonte: Ceale; autêntica, 2007 
FRANÇA, Cintia. Simioni.; BATTINI, Okçana. Formação de professores e politicas publicas educacionais: qual a função das tecnologias de informação e comunicação no espaço escolar? ÁGORA, Porto Alegre, Ano 6, jul/dez.2015.

KENSKI, Vani. Moreira. Tecnologias e ensino presencial e a distância. Campinas: Papirus, 2003.

KLEIMAN, Ângela . Os significados do letramento. Campinas, S.P.: Mercado de Letras, 1995.

LEVY. P. Pierre. Cibercultura. São Paulo: Editora, 2008.

LIBÂNEO, José. Carlos. Prefácio. In: GUIMARÃES, V.S. Formação de Professores: saberes, identidade e profissão. $5^{\mathrm{a}}$ ed. Campinas/SP: Papirus, 2010.

LOPES, M. V. O.; SILVA, V. M.; ARAÚJO, T. L. Observation mediated by computer professional report. Online Braz J Nurs, 2006; 5(2).

MARTINELLI, Maria Lúcia (org): Pesquisa Qualitativa: um instigante desafio. São Paulo, Veras Editora, 1999.

MORAN, José., MASETTO, Marcos. Tarcisio. \& BEHRENS, Marilda. Aparecida. Novas tecnologias e mediação pedagógica. Campinas, SP: Papirus. 2000.

NÓVOA, Antonio. Professores imagens do futuro presente. Lisboa: Educa, 2009.

Disponível: http://www.slideshare.net/mzylb/antonio-novoa-novo-livro

PACHECO, Samuel Bueno. 1997. Internet: As relações de ensino-aprendizagem no hiperespaço. Tecnologia Educacional. v.25, n.136, 137, mai/jun/jul/ago.1997.

PERRENOUD, Phelip. A prática reflexiva no ofício de professor: profissionalização e razão pedagógica. Porto Alegre: Artmed, 2002.

REIS, Maria. Aparecida; NANTES, Eliza Adriana. Sheuer; MACIEL, Cilene, Maria. Lima. Antunes: Letramento digital: uma investigação da teoria à prática docente de professores do estado de Mato Grosso. Instituto Federal de Mato Grosso - Campus Confresa Revista Prática Docente. v. 3, n. 1, p. 249-262, jan/jun 2018.

ROJO, Roxane; ALMEIDA, Eduardo de Moura. Multiletramentos na escola. São Paulo: Parábola Editora, 2012.

ROJO, Roxane; ALMEIDA, Eduardo de Moura. Letramentos múltiplos, escola e inclusão social. São Paulo: Parábola, 2009

SCHEFFER Silva. da Schell, Ana. Paula, RUBIM Pedro., EVA Néri., Autonomia no processo de construção do conhecimento de alunos de enfermagem: o chat educacional como ferramenta de ensino. Revista Latino-Americana de Enfermagem [en linea] 2010, 18 (Abril-Sin mes) : [Fecha de consulta: 13 de octubre de 2018] Disponible en: $\langle$ http://www.redalyc.org/articulo.oa?id=281421932011> 
SCHÖN, Donald. A. Formar professores como profissionais reflexivos. In: NÓVOA, António (Coord). Os professores e a sua formação. 2. ed. Lisboa: Dom Quixote, 1995.

SCHWAB, Klaus. A quarta revolução industrial. Disponível em:

https://webcache.googleusercontent.com/search?q=cache:65nG8zZQNcsJ:https://edisciplinas. usp.br/pluginfile.php/4212041/mod_folder/content $/ 0 /$ Schwab\%2520\%25282016\%2529\%252 0A\%2520quarta\%2520revolucao\%2520industrial.pdf\%3Fforcedownload\%3D1+\&cd=2\&hl= pt-BR\&ct=clnk\&gl=br Acesso em 10/10/2018

SOARES, Magda. Letramento: um tema em três gêneros. 3 ed. Belo Horizonte: Autêntica, 2009.

TANAKA, Raquel Yurika et al . Objeto educacional digital: avaliação da ferramenta para prática de ensino em enfermagem. Acta paul. enferm., São Paulo, v. 23, n. 5, p. 603607, Oct. 2010 . Available from

$<$ http://www.scielo.br/scielo.php?script=sci_arttext\&pid=S0103-

$1002010000500003 \& \operatorname{lng}=$ en\&nrm=iso $>$. access

on 11 Nov. 2018. http://dx.doi.org/10.1590/S0103-21002010000500003.

TAVARES Izaildo.; COSTA Patricia; OLIVEIJO T, F. Hipermídias para o ensino de enfermagem em ambiente digital de aprendizagem. CIET: EnPED, S.1.], maio 2018. ISSN 2316-8722. Disponível em:

$<$ http://cietenped.ufscar.br/submissao/index.php/2018/article/view/207>. Acesso em: 15 jul. 2018 .

VALENTE, José. Armando., "A Telepresença na Formação de Professores da Área de Informática em Educação: Implantando o Construcionismo Contextualizado". Actas do IV Congresso Ibero-Americano de Informática na Educação - RIBIE98, Brasília, CD-Rom, /trabalhos/232.pdt, 1998

Recebido em: 15 de outubro de 2018.

Aprovado em: 25 de novembro de 2018. 